\title{
A Case of Rare Matrix-producing Triple-negative Breast Carcinoma for Which Drug Response in a Patient-derived Orthotopic Xenograft Mouse Model Was Correlated With Patient Response
}

\author{
TSUNEHISA NOMURA ${ }^{1}$, JUNICHI KUREBAYASHI ${ }^{1}$, TAKUYA MORIYA ${ }^{2}$, WATARU SAITO ${ }^{1}$, \\ TAKUYA MURATA ${ }^{3}$, JUN YAMAMOTO ${ }^{4,5}$, CHIHIRO HOZUMI ${ }^{6}$ and ROBERT M. HOFFMAN ${ }^{4,5}$ \\ ${ }^{1}$ Department of Breast and Thyroid Surgery, Kawasaki Medical School, Kurashiki, Japan; \\ ${ }^{2}$ Department of Pathology, Kawasaki Medical School, Kurashiki, Japan; \\ ${ }^{3}$ Department of Obstetrics and Gynecology 2, Kawasaki Medical School, Kurashiki, Japan; \\ ${ }^{4}$ AntiCancer Inc, San Diego, CA, U.S.A.; \\ ${ }^{5}$ Department of Surgery, UCSD, San Diego, CA, U.S.A.; \\ ${ }^{6}$ AntiCancer Japan Inc, Narita, Japan
}

\begin{abstract}
Background: Matrix-producing breast carcinoma $(M P B C)$ is a very rare and usually aggressive triple-negative breast cancer. We successfully established a patient-derived orthotopic xenograft (PDOX) model from a patient with MPBC and used it to study tumor sensitivity to various agents. Case Report: A 40-year-old woman was diagnosed with MPBC with a triple-negative phenotype. Due to axillary lymph-node metastases found during radical mastectomy, the patient was subsequently treated with epirubicin, cyclophosphamide and paclitaxel. In addition, radiotherapy was directed to the chest wall and subclavicular fossa. A portion of the cancer tissue from the mastectomy was used to establish a PDOX nudemouse model. The PDOX model was resistant to paclitaxel, bevacizumab, vinorelbine, cisplatinum and olaparib, and sensitive to eribulin. Metastases in mediastinal lymph nodes and the right ovary were observed in the patient 14 months after mastectomy. Thoracoscopic mediastinal lymph-node biopsy and laparoscopic oophorectomy were performed, and both confirmed breast-cancer metastasis. The patient was then treated with paclitaxel and bevacizumab but no response was
\end{abstract}

This article is freely accessible online.

Correspondence to: Tsunehisa Nomura, MD, Ph.D., Department of Breast and Thyroid Surgery, Kawasaki Medical School, 577 Matsushima, Kurashiki, Okayama, 701-0192, Japan. Tel: +81 864621111, Fax: +81 864621199, e-mail: somoejo@med.kawasakim.ac.jp

Key Words: Matrix-producing breast carcinoma, triple-negative, patient-derived orthotopic xenograft, PDOX, eribulin, paclitaxel, bevacizumab, clinical correlation, concordance. observed, which correlated with the inability of these drugs to arrest tumor growth in the PDOX models of the patient's tumor. The patient was then given eribulin based on the PDOX-model result, but treatment had to be stopped because of rapid progression of metastasis into the cervical lymph nodes and thyroid gland. The patient was subsequently treated with atezolizumab and nab-paclitaxel. Unfortunately, the patient died of her cancer 8 months after recurrence. Conclusion: The present study demonstrates that the PDOX model of a patient's triple-negative MPBC accurately predicted that paclitaxel and bevacizumab would not arrest the patient's tumor growth. Eribulin may have been effective if administered at an earlier stage of the patient's cancer course. Drug-screening results from PDOX models should be used as early as possible in order to improve patient outcome.

Matrix-producing breast carcinoma (MPBC) is an extremely rare histological subtype of breast cancer (1). MPBC occurs in $0.1 \%$ of Japanese breast-cancer cases (2) and $0.03-0.2 \%$ of cases worldwide (3). Most MPBCs are triple-negative, not expressing estrogen receptor (ER), progesterone receptor (PgR) or human epidermal growth factor receptor 2 (HER2). MPBC is known to directly invade muscle cartilage or bone matrix without the involvement of a spindle-cell component (4).

Predicting the efficacy of antitumor agents is an area of great importance for individualized cancer therapy. Patientderived orthotopic xenograft (PDOX) models, in which the in vivo human environment is closely mimicked by transplanting intact cancer tissue orthotopically into immunodeficient mice, have been used to identify both active and inactive drugs for patient tumors (5). The first study of breast cancer with a PDOX model was conducted by Fu et al. in 1993 (6). 
We previously successfully established a PDOX model of a triple-negative chemoresistant MPBC and found that the PDOX tumor was resistant to paclitaxel, bevacizumab, vinorelbine, cisplatinum and olaparib and sensitive to eribulin $(7,8)$. Eribulin was used for the treatment of the present patient whose tissue was used for the PDOX model but efficacy was not shown due to the rapid progression of advanced disease. The PDOX model showed concordance with the behavior of the patient's tumor as both were resistant to paclitaxel and bevacizumab.

\section{Case Report}

Findings on initial examination. The patient was a 40-yearold woman who presented at the Kawasaki Medical School with a left-breast mass that she had observed 1 month earlier. Needle-biopsy analysis showed suspected metaplastic carcinoma. A $2.6-\mathrm{cm}$ mass was palpated in the upper-outer quadrant of the left breast. The left-axillary lymph node was not palpable.

An indistinct mass with pleomorphic microcalcification was seen on mammography, and breast ultrasonography showed a lobulated and hypoechoic mass that was welldefined with a rough border and a somewhat heterogeneous echo in internal structure was seen (Figure 1A). Contrastenhanced computed tomography (CT) revealed a ringenhanced shadow in the left breast, with no obvious metastasis (Figure 1B). Contrast-enhanced breast magnetic resonance imaging demonstrated a high-intensity ringenhanced lesion in the left breast (Figure 1C).

Based on these findings, the patient was diagnosed as having a primary breast cancer and underwent left modifiedmastectomy and axillary lymph-node dissection. The Institutional Ethics Committee of Kawasaki Medical School approved PDOX studies (approval number 1975-7), and written, informed consent was obtained from the patient. The tissue used for the PDOX model was part of the tumor and resected as an approximately $2 \times 2 \mathrm{~cm}^{2}$ block at the time of mastectomy. A freshly-resected tumor specimen was implanted into a large subcutaneous pocket in nude mice using the method of Hozumi [described in (9)].

Pathological diagnosis. The resected tumor was a relatively well-circumscribed invasive carcinoma, $17 \mathrm{~mm}$ in diameter. It comprised trabecular cell nests. Viable cancer cells were located on the periphery of the tumor, and a chondromyxoid matrix was attached on the inside. The histological diagnosis was metaplastic carcinoma (matrix-producing carcinoma) (Figure 2). The nuclei were high grade and histological grade was 3. Immunohistochemically, the tumor was triplenegative. The Ki67 labeling index was 70.0\%. Extensive lymphovascular invasion was seen, and metastasis to two axillary lymph nodes was observed.
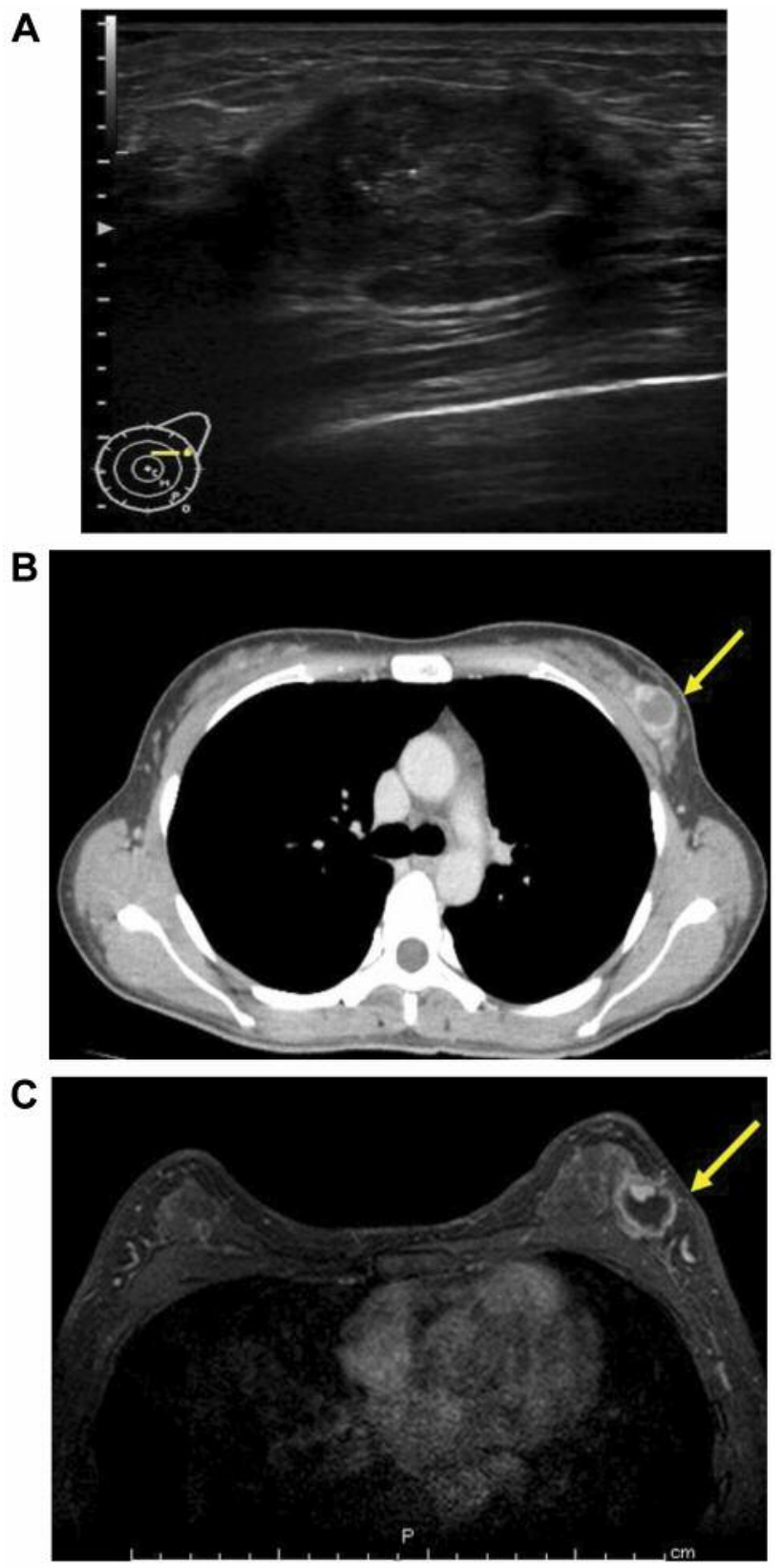

Figure 1. Matrix-producing breast carcinoma imaging findings. A: Breast ultrasound sonogram showed a lobulated hypoechoic mass that was well-defined with a rough border and heterogeneous echo in internal structure. B: Contrast-enhanced computed tomography revealed a peripheral ring enhancement (arrow) in the breast tumor. $C$ : Contrast-enhanced T2-weighted magnetic resonance imaging showed a ring-enhanced appearance in the tumor (arrow).

Postoperative course. The patient received four courses of epirubicin $\left(100 \mathrm{mg} / \mathrm{m}^{2}\right)$ and cyclophosphamide $\left(750 \mathrm{mg} / \mathrm{m}^{2}\right)$. Thereafter, weekly paclitaxel $\left(80 \mathrm{mg} / \mathrm{m}^{2}\right)$ was started, but the treatment was terminated because of severe neutropenia. 

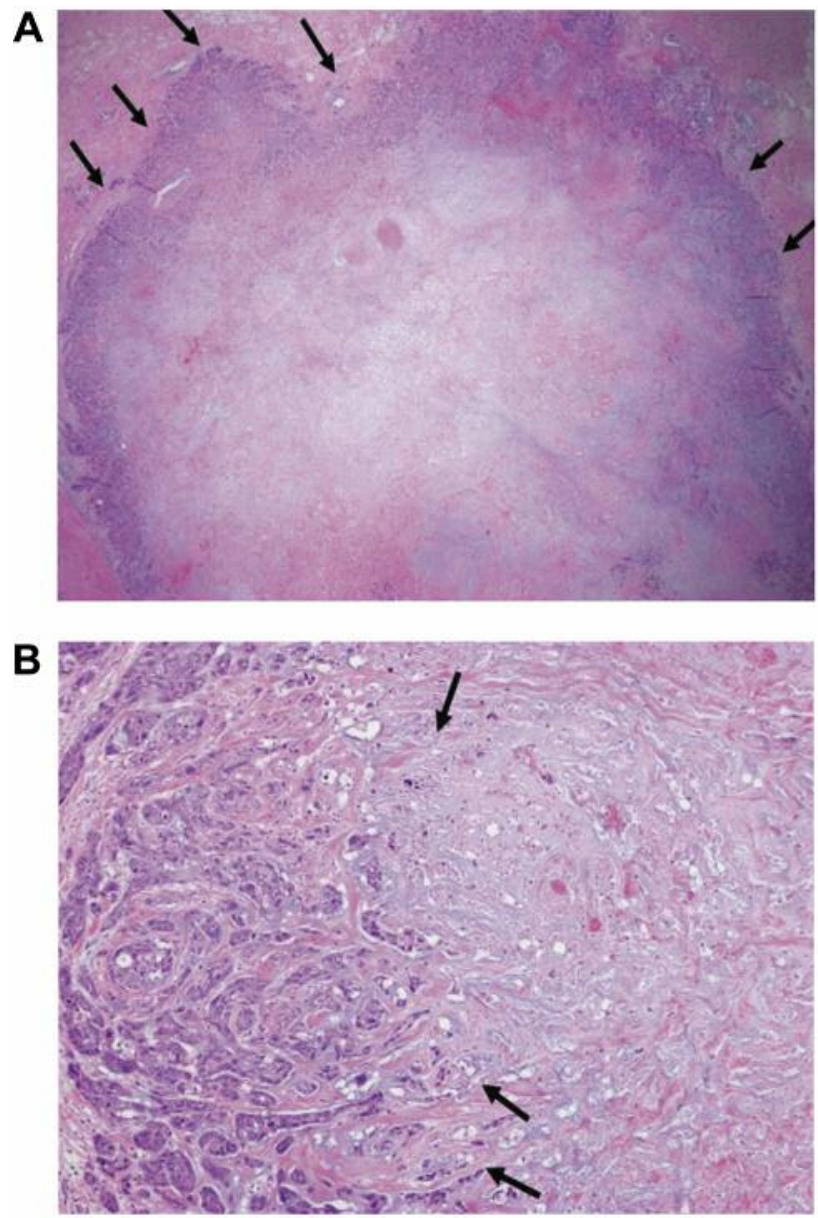

Figure 2. Matrix-producing breast carcinoma microscopic findings (hematoxylin and eosin staining). A: The tumor was relatively wellcircumscribed, and viable cancer cells were located on the periphery (arrows) (x20). B: Invasive carcinoma, with trabecular cell nests, was seen, and a chondromyxoid matrix was attached (arrows) $(\times 100)$.

Radiotherapy with a total of 50 Gy was administered to the chest wall and supraclavicular area. There were subsequently no subjective symptoms, but chest and abdominal CT performed at regular follow-up exams showed enlarged mediastinal lymph nodes and a mass on the right ovary. Positron-emission tomography/CT scanning also showed a strong signal in the mediastinal lymph nodes and a mass on the right ovary. Thoracoscopic mediastinal lymph-node biopsy was performed, and the diagnosis was suspected metastatic carcinoma expressing cytokeratins 7 and 20, but not transcription-termination factor 1 . Both ovaries were removed by laparoscopic surgery. The right ovary was found to have been totally replaced by metastatic tumor (Figure 3 ). In addition, staining for programmed cell-death ligand 1 (PD-L1; clone SP142) was positive (1-4\% of tumorinfiltrating immune cells) at the metastatic site.
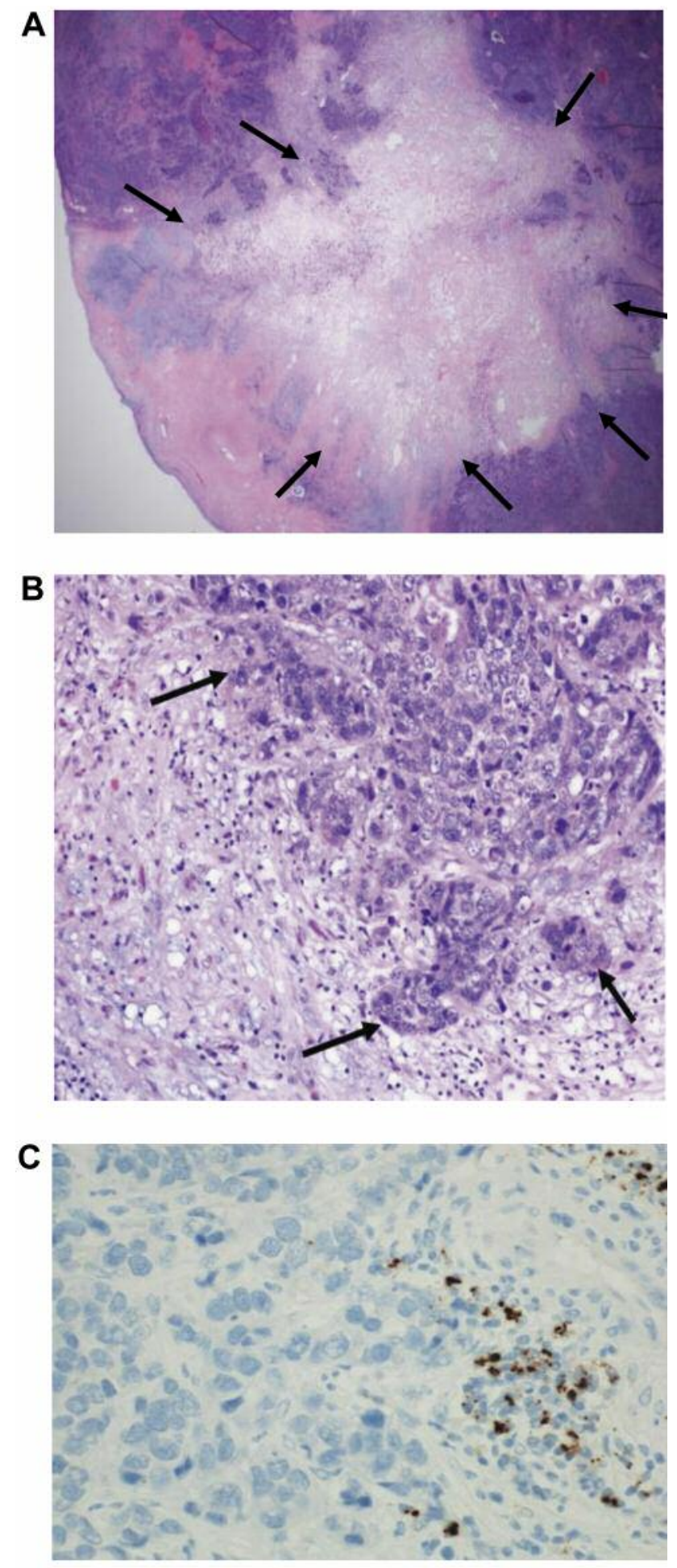

Figure 3. Metastatic carcinoma of the ovary. A: The right ovary was enlarged and was totally replaced by metastatic tumor (arrows) (hematoxylin and eosin staining, x20). B: The tumor histology was consistent with metastatic breast carcinoma (arrows)(hematoxylin and eosin staining, $\times 200)$. C: Programmed cell-death ligand 1 (PD-L1; clone SP142; $\times 400)$ staining was positive for tumor-infiltrating immune cells (black stain). 

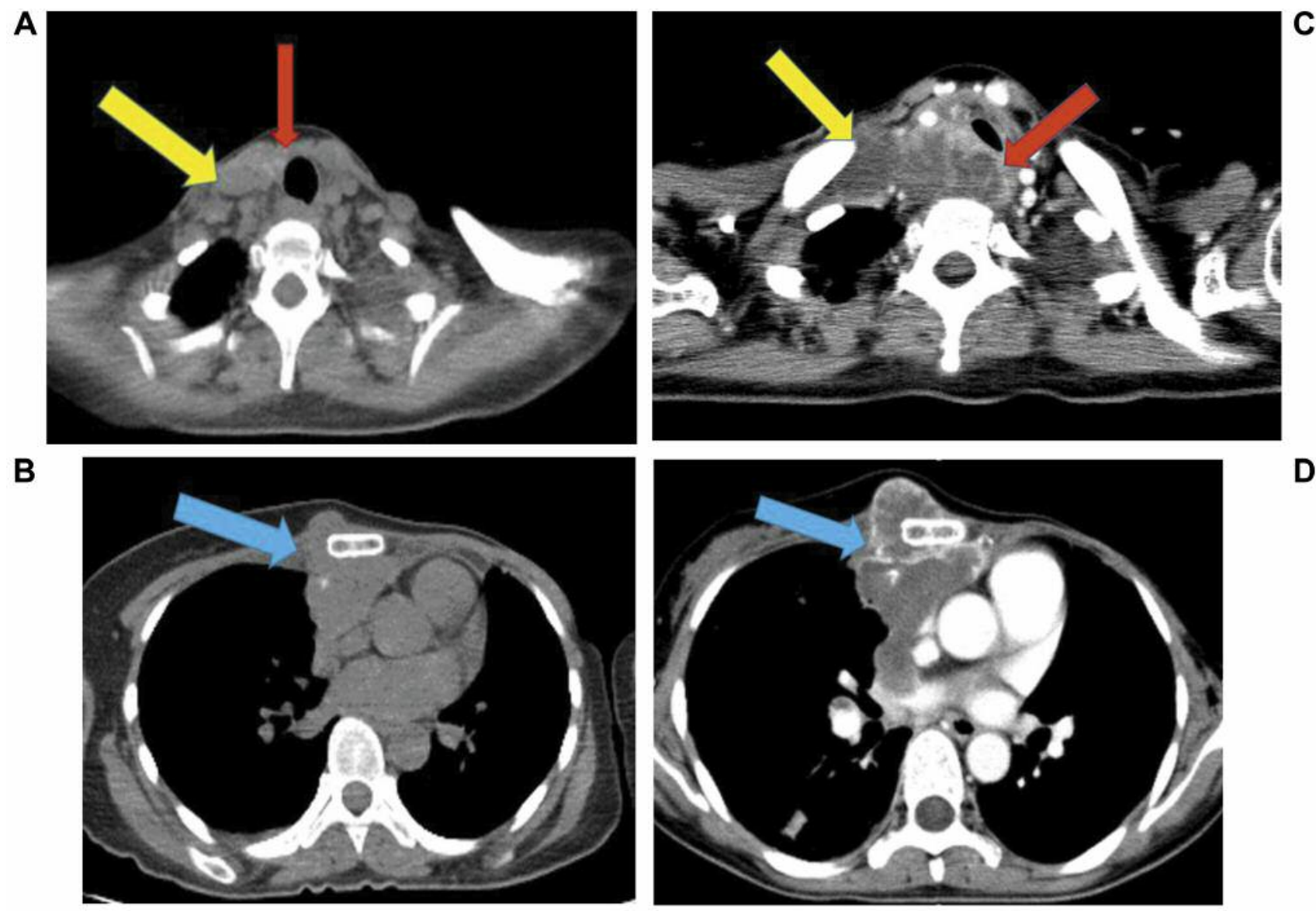

Figure 4. Computed tomography images before $(A, B)$ and after $(C, D)$ eribulin therapy. A rapid enlargement of the thyroid gland (red arrows) and cervical (yellow arrows) and mediastinal lymph nodes (blue arrows) was observed after eribulin therapy.

The patient then received combination paclitaxel with bevacizumab therapy. Brain metastases were subsequently found, and gamma-knife therapy was performed for the brain metastases.

At this time, results from drug testing in the PDOX model of the patient's tumor became available and showed that neither paclitaxel nor bevacizumab arrested the growth of the PDOX tumor, consistent with results of the patient's therapy. Eribulin led to PDOX tumor regression $(7,8)$. A single course of eribulin was administered to the patient. However, rapid enlargement of the thyroid gland and cervical and mediastinal lymph nodes was observed and caused tracheal stenosis (Figure 4). Eribulin was probably administered too late in the course of the patient's disease to be effective. Subsequent, atezolizumab combined with nab-paclitaxel was given to the patient, based on PD-L1 positivity of the metastatic lesions. This treatment was also ineffective, and the patient died of her cancer 8 months after recurrence.

\section{Discussion}

MPBC is an extremely rare histological subtype of breast cancer with a unique morphology, which was first reported by Wargotz et al. (1). In Japan, Kusafuka et al. reported the prevalence of MPBC, among all invasive breast cancer cases, as only $0.2 \%$ (2). The World Health Organization (fifth edition) classifies MPBC as a metaplastic carcinoma with mesenchymal differentiation (10). The characteristic imaging findings of MPBC were reported to be rim enhancement on CT and magnetic resonance imaging (11), and these findings were observed in the present case.

Most MPBCs are negative for ER, PgR, and HER2 (triplenegative), as was the present case (11-13). Ouchi et al. reported the Ki67 labeling index of nine MPBC cases to be in the range of $20-90 \%$ (median value of 69\%) (14). In the present case, the Ki67 index was 70\%. In addition, the metastatic lesion in the ovary was positive for PD-L1 (1-4\% of tumor infiltrating Tcells). To the best of our knowledge, the present case is the first 
MPBC in which PD-L1 was evaluated. It was not possible to fully judge the therapeutic effect of atezolizumab because it was given to the patient just before she died. Further study of atezolizumab in MPBC is indicated.

Wargotz et al. reported a 5-year survival rate of $68 \%$ for patients with MPBC, which is worse than common invasive ductal breast cancer (1). In contrast, a good prognosis was reported in 10 cases by Krings et al. (15), in eight cases by Yamaguchi et al. (16), and in 13 cases by Shui et al. (12), with no recurrence in any of these cases. None of the latter three studies reported lymph-node metastasis, in contrast to the present case.

The report compiling the largest number of cases of MPBC is that of Downs-Kelly et al. (17), who found that local recurrence and distant metastasis were significantly more frequent in MPBC cases than in common invasive ductal breast cancer.

The present case was a hepatitis B-virus carrier, receiving tenofovir disoproxil fumarate to prevent the development of fulminant hepatitis. Postoperative adjuvant therapy consisted of four courses of epirubicin and cyclophosphamide followed by radiotherapy of $50 \mathrm{~Gy}$ and three courses of weekly paclitaxel. Paclitaxel therapy was suspended after three courses due to severe neutropenia. Nonetheless, the time until recurrence was short, at only 26 months after surgery and 16 months after completion of paclitaxel.

The factors predicting the prognosis of MPBC were stated by Wargotz et al. (1) and Rakha et al. (18) to include age, tumor size, vascular invasion, and cell density. The present case was a young patient with age at onset of 40 years. Pathologically, the invasive diameter was $17 \mathrm{~mm}$, but this measurement was taken during surgery, following harvesting of a $2 \times 2 \mathrm{~cm}^{2}$ tumor block for PDOX establishment; and the primary was in fact considered to be over $2 \mathrm{~cm}$ in diameter. Lymph-node metastasis was observed, and lymphatic invasion was extensive; therefore, all the factors for a poor prognosis were present. Han et al. reported that progression-free survival, overall survival, distant-relapse-free survival, and breast-cancer-specific survival were worse with larger tumor size and the presence of lymph-node metastasis in 97 cases of metaplastic carcinoma, including 31 cases of MPBC (19).

Epithelial-mesenchymal transition (EMT) has been reported to be a factor related to poor prognosis of metaplastic carcinoma (20). Eribulin is reported to inhibit EMT (21), and this may be related to the efficacy of eribulin in our PDOX model.

Immunostaining of a preoperative needle biopsy in the present case showed a triple-negative subtype; however, MPBC was strongly suspected on the basis of the imaging findings and the pathological results of the needle biopsy, and it was decided to proceed with surgery.

Shimada et al. reported the results of five cases of MPBC treated with neo-adjuvant chemotherapy using an anthracycline and docetaxel. There were no pathological-complete response (pCR) cases, and most were resistant to treatment (22). Han et al. examined the response to neo-adjuvant chemotherapy in 97 cases of metaplastic carcinoma, which included 17 MPBC cases, of which four (23.5\%) showed pCR (19).

In our previous studies, we established a PDOX model from the present patient's MPBC. This PDOX model was used to study sensitivity to various agents, including paclitaxel and bevacizumab $(7,8)$. Paclitaxel and bevacizumab did not arrest tumor growth in the PDOX model, consistent with the results in the patient $(7,8)$.

Based on the PDOX results, eribulin was used for the treatment of recurrent disease in the present case. Unfortunately, no clinical benefit was obtained because at the time of eribulin administration, metastasis to the ovaries, distant lymph nodes, thyroid gland and brain had already occurred, and the patient's condition was rapidly deteriorating.

In the present case, paclitaxel with bevacizumab was selected as first-line chemotherapy at the time of recurrence, but no therapeutic effect was obtained. This correlated with the PDOX response to these drugs. The patient's survival may have been prolonged had eribulin been administered at an earlier stage.

A monoclonal antibody to PD-L1, atezolizumab, was administered based on a positive immunostaining for PD-L1 in the ovarian metastasis. However, no therapeutic effect was obtained. Although the IMpassion130 study recently showed a significant prolongation of progression-free survival by the addition of atezolizumab to chemotherapy in patients with unresectable triple-negative breast cancer (23), as far as we are aware, there are no previous reports on the efficacy of atezolizumab on metaplastic carcinoma, including MPBC. There is a need for research into the PD-L1 expression status in MPBC and other metaplastic carcinomas.

PDOX models accurately represent the tumor microenvironment and have thus shown high correlation with patient drug response $(24,25)$. With the recent development of implantation of large amounts of tumor surrounded by normal tissue in nude mice to greatly increases the frequency of PDOX establishment by our laboratory (9), we can expect PDOX model establishment for many more patients in the future to identify both effective and ineffective drugs for each patient.

\section{Conclusion}

We successfully established a PDOX model from a very rare triple-negative MPBC and used this model to screen a panel of candidate therapeutics for the patient. The PDOX model demonstrated that paclitaxel and bevacizumab were unable to arrest the tumor, which was in concordance with the results of therapy in the patient. Eribulin was identified in the PDOX model as effective but was administered too late in the course of the patient's disease. The present study demonstrates the 
potential clinical usefulness of PDOX models and highlights the need to use the drug-sensitivity results of the PDOX model as early as possible in the course of the patient's disease.

\section{Conflicts of Interest}

The Authors declare that they have no conflicts of interest regarding the publication of this article. Anticancer Inc. uses PDOX models for cancer research. JY, CH and RMH are unsalaried associates of AntiCancer Inc.

\section{Authors' Contributions}

TN, TM and RMH conceived the original idea. TN wrote the article with support from JK, TM and RMH. RMH and JK contributed to the interpretation of the results. RMH supervised the project and contributed to the final version of the article. TN, WS and TM planned and carried out the simulations. JYH, TMu and RMH developed and refined PDOX models. TM diagnosed all histopathological findings.

\section{References}

1 Wargotz ES and Norris HJ: Metaplastic carcinomas of the breast. I. Matrix-producing carcinoma. Hum Pathol 20(7): 628-635, 1989. PMID: 2544506. DOI: 10.1016/0046-8177(89)90149-4

2 Kusafuka K, Muramatsu K, Kasami M, Kuriki K, Hirobe K, Hayashi I, Watanabe H, Hiraki Y, Shukunami C, Mochizuki T and Kameya T: Cartilaginous features in matrix-producing carcinoma of the breast: four cases report with histochemical and immunohistochemical analysis of matrix molecules. Mod Pathol 21(10): 1282-1292, 2008. PMID: 18622387. DOI: 10.1038/ modpathol.2008.120

3 Lakhani SR, Ellis IO, Schnitt SJ, Tan PH, van de Vijver MJ: WHO Classification of Tumours of the Breast 4th Edition, Volume 4. Lakhani SR, Ellis IO, Schnitt SJ, Tan PH and van de Vijver MJ (eds.). IARC Publications, 2012.

4 Sari A, Çakalagaoğlu F, Altinboğa AA, Kucukzeybek BB, Calli A and Atahan MK: Cytopathological features of matrixproducing carcinoma of the breast. J Cytol 32(1): 33-35, 2015. PMID: 25948943. DOI: 10.4103/0970-9371.155231

5 Hoffman RM: Patient-derived orthotopic xenografts: better mimic of metastasis than subcutaneous xenografts. Nat Rev Cancer 15(8): 451-452, 2015. PMID: 26422835. DOI: $10.1038 / \mathrm{nrc} 3972$

$6 \mathrm{Fu} \mathrm{X,} \mathrm{Le} \mathrm{P} \mathrm{and} \mathrm{Hoffman} \mathrm{RM:} \mathrm{A} \mathrm{metastatic} \mathrm{orthotopic-transplant}$ nude-mouse model of human patient breast cancer. Anticancer Res 13(4): 901-904, 1993. PMID: 8352558.

7 Yamamoto J, Murata T, Tashiro Y, Higuchi T, Sugisawa N, Nishino H, Inubushi S, Sun YU, Lim H, Miyake K, Hongo A, Nomura T, Saitoh W, Moriya T, Tanino H, Hozumi C, Bouvet M, Singh SR, Endo I and Hoffman RM: A triple-negative matrix-producing breast carcinoma patient-derived orthotopic xenograft (PDOX) mouse model is sensitive to bevacizumab and vinorelbine, regressed by eribulin and resistant to olaparib. Anticancer Res 40(5): 2509-2514, 2020. PMID: 32366395. DOI: 10.21873/anticanres.14221

8 Yamamoto J, Murata T, Sugisawa N, Higuchi T, Tashiro Y, Nishino H, Inubushi S, Sun YU, Lim H, Miyake K, Shimoya K, Nomura T, Kurebayashi J, Tanino H, Hozumi C, Bouvet M,
Singh SR, Endo I and Hoffman RM: Eribulin regresses a cisplatinum-resistant rare-type triple-negative matrix-producing breast carcinoma patient-derived orthotopic xenograft mouse model. Anticancer Res 40(5): 2475-2479, 2020. PMID: 32366391. DOI: 10.21873 /anticanres.14217

9 Murata T, Hozumi C, Hiroshima Y, Shimoya K, Hongo A, Inubushi S, Tanino H and Hoffman RM: Co-implantation of tumor and extensive surrounding tissue improved the establishment rate of surgical specimens of human-patient cancer in nude mice: Toward the goal of universal individualized cancer therapy. In Vivo 34(6): 3241-3245, 2020. PMID: 33144429. DOI: 10.21873/invivo.12160

10 WHO Classification of Tumours Editorial Board: Breast Tumours. WHO Classification of Tumours 5th Edition, Volume 2. IARC Publications, 2019.

11 Okuyama N, Sakamoto G, Sasaki T, Tokutome N, Sarumaru S, Hori F, Horii R, Akiyama F and Kasumi F: Clinicopathological features of matrix-producing carcinoma. Jpn J Breast Cancer 19: 339-342, 2004.

12 Shui R, Bi R, Cheng Y, Lu H, Wang J and Yang W: Matrixproducing carcinoma of the breast in the Chinese population: a clinicopathological study of 13 cases. Pathol Int 61(7): 415422, 2011. PMID: 21707845. DOI: 10.1111/j.14401827.2011.02676.x

13 Yamaguchi R, Tanaka M, Kondo K, Yokoyama T, Maeda I, Tsuchiya S, Yamaguchi M, Takahashi R, Ogata Y, Abe H, Akiba J, Nakashima O, Kage $\mathrm{M}$ and Yano H: Immunohistochemical study of metaplastic carcinoma and central acellular carcinoma of the breast: central acellular carcinoma is related to metaplastic carcinoma. Med Mol Morphol 45(1): 14-21, 2012. PMID: 22431179. DOI: $10.1007 / \mathrm{s} 00795-010-0536-\mathrm{x}$

14 Ouchi Y, Konishi E, Sakaguchi K, Nakatsukasa K, Fujita Y, Kiba M, Goto M, Kaoku S, Yamazaki S and Taguchi T: A case of matrix-producing breast carcinoma, showing favorable correspondence between imaging and histological features. Jpn J Breast Cancer 30(4): 327-334, 2015.

15 Krings $\mathrm{G}$ and Chen YY: Genomic profiling of metaplastic breast carcinomas reveals genetic heterogeneity and relationship to ductal carcinoma. Mod Pathol 31(11): 1661-1674, 2018. PMID: 29946183. DOI: $10.1038 / \mathrm{s} 41379-018-0081-\mathrm{z}$

16 Yamaguchi R, Horii R, Maeda I, Suga S, Makita M, Iwase T, Oguchi M, Ito Y and Akiyama F: Clinicopathologic study of 53 metaplastic breast carcinomas: their elements and prognostic implications. Hum Pathol 41(5): 679-685, 2010. PMID: 20153509. DOI: 10.1016/j.humpath.2009.10.009

17 Downs-Kelly E, Nayeemuddin KM, Albarracin C, Wu Y, Hunt KK and Gilcrease MZ: Matrix-producing carcinoma of the breast: an aggressive subtype of metaplastic carcinoma. Am J Surg Pathol 33(4): 534-541, 2009. PMID: 19047898. DOI: 10.1097/PAS.0b013e31818ab26e

18 Rakha EA, Tan PH, Shaaban A, Tse GM, Esteller FC, van Deurzen CH, Purnell D, Stotter A, Chan T, Yamaguchi R, Dodwell D, Jager A, Soler MT, Juneinah E, Plaza ML, Hodi Z, McCulloch T, Lee AH and Ellis IO: Do primary mammary osteosarcoma and chondrosarcoma exist? A review of a large multi-institutional series of malignant matrix-producing breast tumours. Breast 22(1): 13-18, 2013. PMID: 23084962. DOI: 10.1016/j.breast.2012.09.010

19 Han M, Salamat A, Zhu L, Zhang H, Clark BZ, Dabbs DJ, Carter GJ, Brufsky AM, Jankowitz RC, Puhalla SL, Johnson RR, Soran A, Steiman JG, McAuliffe PF, Diego EJ and Bhargava R: 
Metaplastic breast carcinoma: a clinical-pathologic study of 97 cases with subset analysis of response to neoadjuvant chemotherapy. Mod Pathol 32(6): 807-816, 2019. PMID: 30723293. DOI: 10.1038/s41379-019-0208-x

20 Lien HC, Hsiao YH, Lin YS, Yao YT, Juan HF, Kuo WH, Hung MC, Chang KJ and Hsieh FJ: Molecular signatures of metaplastic carcinoma of the breast by large-scale transcriptional profiling: identification of genes potentially related to epithelialmesenchymal transition. Oncogene 26(57): 7859-7871, 2007 PMID: 17603561. DOI: 10.1038/sj.onc.1210593

21 Dezső Z, Oestreicher J, Weaver A, Santiago S, Agoulnik S, Chow J, Oda Y and Funahashi Y: Gene expression profiling reveals epithelial mesenchymal transition (EMT) genes can selectively differentiate eribulin sensitive breast cancer cells PLoS One 9(8): e106131, 2014. PMID: 25171249. DOI: 10.1371/journal.pone.0106131

22 Shimada K, Ishikawa T, Yamada A, Sugae S, Narui K, Shimizu D, Chishima $\mathrm{T}$ and Endo I: Matrix-producing carcinoma as an aggressive triple-negative breast cancer: Clinicopathological features and response to neoadjuvant chemotherapy. Anticancer Res 39(7): 3863-3869, 2019. PMID: 31262914. DOI: 10.21873/ anticanres. 13536

23 Schmid P, Rugo HS, Adams S, Schneeweiss A, Barrios CH, Iwata H, Diéras V, Henschel V, Molinero L, Chui SY, Maiya V, Husain A, Winer EP, Loi S, Emens LA and IMpassion 130 Investigators: Atezolizumab plus nab-paclitaxel as first-line treatment for unresectable, locally advanced or metastatic triplenegative breast cancer (IMpassion130): updated efficacy results from a randomised, double-blind, placebo-controlled, phase 3 trial. Lancet Oncol 21(1): 44-59, 2020. PMID: 31786121. DOI: $10.1016 / \mathrm{S} 1470-2045(19) 30689-8$
24 Miyake K, Murakami T, Kiyuna T, Igarashi K, Kawaguchi K, Miyake M, Li Y, Nelson SD, Dry SM, Bouvet M, Elliott IA, Russell TA, Singh AS, Eckardt MA, Hiroshima Y, Momiyama M, Matsuyama R, Chishima T, Endo I, Eilber FC and Hoffman RM: The combination of temozolomide-irinotecan regresses a doxorubicin-resistant patient-derived orthotopic xenograft (PDOX) nude-mouse model of recurrent Ewing's sarcoma with a FUS-ERG fusion and $C D K N 2 A$ deletion: Direction for thirdline patient therapy. Oncotarget 8(61): 103129-103136, 2017. PMID: 29262551. DOI: 10.18632/oncotarget.20789

25 Murakami T, Singh AS, Kiyuna T, Dry SM, Li Y, James AW, Igarashi K, Kawaguchi K, DeLong JC, Zhang Y, Hiroshima Y, Russell T, Eckardt MA, Yanagawa J, Federman N, Matsuyama R, Chishima T, Tanaka K, Bouvet M, Endo I, Eilber FC and Hoffman RM: Effective molecular targeting of CDK4/6 and IGF-1R in a rare FUS-ERG fusion CDKN2A-deletion doxorubicin-resistant Ewing's sarcoma patient-derived orthotopic xenograft (PDOX) nude-mouse model. Oncotarget 7(30): 47556-47564, 2016. PMID: 27286459. DOI: $10.18632 /$ oncotarget.9879
Received September 15, 2021

Revised September 23, 2021

Accepted September 29, 2021 